SUBJECT AREAS:

EXPERIMENTAL MODELS

OF DISEASE

HOMEOSTASIS

Received

2 April 2014

Accepted

11 June 2014

Published

3 July 2014

Correspondence and requests for materials should be addressed to

Q.-Y.Z. (zhangq@ wadsworth.org) or

N.J.M. (nicholas. mantis@health.ny.gov)

\footnotetext{
* These authors contributed equally to this work.
} \section{Cytochrome P450 Reductase are Prone to Acute Toxin-induced Mucosal Damage}

\author{
Sarita Ahlawat ${ }^{1 *}$, Fang Xie ${ }^{2 *}$, Yi Zhu ${ }^{2,3}$, Rebecca D'Hondt ${ }^{1}$, Xinxin Ding ${ }^{2,3,4}$, Qing-Yu Zhang ${ }^{2,3}$ \\ \& Nicholas J. Mantis ${ }^{1,4}$
}

\begin{abstract}
'Division of Infectious Diseases, Wadsworth Center, New York State Department of Health, Albany, NY, ${ }^{2}$ Division of Environmental Health Sciences, Wadsworth Center, New York State Department of Health, Albany, NY, ${ }^{3}$ Departments of Environmental Health Sciences, University at Albany, Albany, NY 12208, ${ }^{4}$ Biomedical Sciences, University at Albany, Albany, NY 12208.
\end{abstract}

Cytochrome P450 (P450) enzymes are a superfamily of heme-containing enzymes involved in the metabolism of various endogenous compounds, including retinoids, glucocorticoids, and eicosanoids, that are postulated to participate in the maintenance and/or development of inflammatory and immune reactions in the intestinal mucosa. To investigate the role of P450 enzymes in intestinal inflammation and immunity, we took advantage of IE-Cpr-null mice, which are deficient in intestinal epithelium of NADPH-cytochrome $\mathbf{P} 450$ reductase (CPR), the obligate redox partner of all microsomal P450 enzymes. We report that IE-Cpr-null mice, following an acute toxin challenge, had higher levels of pro-inflammatory chemokines and increased tissue damage compared to wild-type mice. IE-Cpr-null mice had normal Peyer's patch numbers and elicited normal secretory IgA (SIgA) responses. However, SIgA baseline levels in IE-Cpr-null mice were consistently elevated over WT littermates. While neither retinoic acid nor glucocorticoid levels in serum and intestinal homogenates were altered in IE-Cpr-null mice, basal levels of arachidonic acid metabolites (11,12-DiHETE and 14,15-DiHETE) with known anti-inflammatory property were significantly lower compared to WT controls. Overall, these findings reveal immunological and metabolic changes resulting from a genetic deficiency in CPR expression in the intestine, and support a role for microsomal P450 enzymes in mucosal homeostasis and immunity.

T

he gastrointestinal (GI) epithelium is the largest continuous mucosal surface in the human body. In the small intestine, the GI epithelium consists almost entirely of absorptive enterocytes, which are columnar shaped cells joined side-by-side at their apical aspects by tight junctions $(\mathrm{TJ})^{1-3}$. Absorptive enterocytes are responsible for the bulk of nutrient absorption that occurs in the gut. In addition, absorptive enterocytes function as a barrier that is integral to GI physiology and homeostasis. TJs, for example, limit the paracellular leakage of solutes and macromolecules from the interstitium to the intestinal lumen. The apical surfaces of absorptive enterocytes, which are coated with a 400-500 nm thick meshwork referred to as the filamentous brush border glycocalyx (FBBG), is postulated to function in host defense by limiting access of plant- and microbe-derived toxins and pathogens to epithelial cell receptors ${ }^{4-6}$. In the event that infection or intoxication does occur, absorptive enterocytes are capable of secreting inflammatory chemokines, cytokines and lipid mediators as a strategy to coordinate the innate and adaptive responses to the biological insult ${ }^{7-9}$.

Cytochrome P450 enzymes (P450s) are involved in the metabolism of both xenobiotic and endogenous molecules. Expression of numerous P450 enzymes has been detected in the small intestine at the mRNA and/ or protein levels and the activities of these enzymes are thought to be integral to GI homeostasis ${ }^{10}$. To determine the in vivo function of intestinal epithelial P450s, we recently produced a mouse strain in which the intestinal epithelial P450 activities were abolished via tissue-specific deletion of the gene encoding cytochrome P450 reductase (CPR), the obligate electron donor for all microsomal P450 ${ }^{11}$. These so-called IE-Cpr-null mice do not display any obvious abnormalities in growth, development, or reproduction, and have a normal intestinal epithelium, according to routine histological and morphological analyses. However, they have been shown to be deficient in the first-pass metabolism of oral drugs and dietary contaminants ${ }^{11-14}$. In addition, the IE-Cpr-null mice display increased intestinal tissue levels of intermediates in cholesterol biosynthesis, including farnesyl pyrophosphate (FPP) and geranylgeranyl pyrophosphate (GGPP), and up-regulation in the expression of the major histocompatibility complex class II (MHC II) genes, which are important for intestinal immunity ${ }^{15}$. 
Conceivably, the consequences of the CPR deletion may have additional functional effects on the capacity of the intestinal epithelium to respond to various environmental challenges, such as enterotoxin exposure and infection.

In this study we report that IE-Cpr-null mice are altered in their acute response to the plant-derived toxin, ricin. Following ricin exposure, IE-Cpr-null mice had elevated levels of the pro-inflammatory chemokine MCP-1 and increased tissue damage, as compared to wild-type (WT) mice. In terms of mucosal immunity, IE-Cpr-null mice had normal Peyer's patch numbers and were unaffected in their capacity to elicit a secretory $\operatorname{IgA}(\mathrm{SIgA})$ antibody response following intragastric immunization with a well-characterized antigen. However, SIgA baseline levels in IE-Cpr-null mice were elevated over WT littermate controls, suggesting a role for intestinal P450 enzymes in regulating mucosal homeostasis and immunity. Additionally, we compared between IE-Cpr-null and WT mice for serum and intestinal tissue levels of several endogenous compounds with potential regulatory roles in mucosal inflammation or immunity, and we observed significantly decreased levels of two P450-produced arachidonic acid metabolites (11,12-DiHETE and 14,15-DiHETE) in the intestinal epithelium of the IE-Cpr-null mice.

\section{Results}

IE-Cpr-null mice are hypersensitive to acute intragastric toxin exposure. As the intestinal epithelium is constantly exposed to a variety of biological insults, including microbial pathogens and plant- and bacterial-derived toxins, we sought to investigate the role of P450 enzymes in protecting the epithelium from those types of agents. We initially assessed the ability of IE-Cpr-null mice to defend against the invasive bacterial pathogen, Salmonella enterica serovar Typhimurium (S. Typhimurium). Groups of IECpr-null and age-matched, wild-type (WT) control littermates were challenged intragastrically with a low $\left(1 \times 10^{8}\right.$ colony forming units; CFU) or high $\left(1 \times 10^{10} \mathrm{CFU}\right)$ dose of $S$. Typhimurium. The animals were euthanized $24 \mathrm{hr}$ later and we enumerated CFUs in spleen, as well as Peyer's patch and nonPeyer's patch-containing segments of the small intestines. There was no difference in CFUs recovered from IE-Cpr-null mice as compared to control mice (data not shown). Nor were there any detectable differences in histopathology following $S$. Typhimurium between IE-Cpr-null and control mice, suggesting (at least preliminarily) that the absence of epithelial CPR does not alter the innate mucosal response to invasive enteric pathogens. In a separate study we are pursuing studies using $S$. Typhimurium expressing ovalbumin- and flagellin-derived peptides to evaluate whether or not IE-Cpr-null are affected in eliciting the onset of antigenspecific systemic and mucosal $\mathrm{T}$ and $\mathrm{B}$ cells $\mathrm{s}^{16,17}$.

We next examined the response of IE-Cpr-null mice to the plantderived toxin, ricin. We previously established an acute model of intragastric ricin challenge that results in dose- and time-dependent damage to intestinal villi and a localized increase in the production of the pro-inflammatory chemokine MCP- $1{ }^{18}$. Ricin, derived from the castor bean plant (Ricinus communis), is a member of the ubiquitous ribosome-inactivating protein (RIP) family of toxins that includes Shiga toxins from Escherichia coli ${ }^{19,20}$. Groups of IE-Cpr-null mice and age-matched WT counterparts were challenged by gavage with ricin toxin $(5 \mathrm{mg} / \mathrm{kg})$. Groups of animals were euthanized at time points ranging from 12 to $60 \mathrm{hr}$ later and tissues were collected for histopathology and MCP-1 analysis, as described in the Materials and Methods. Microscopic evaluation of hematoxylin and eosin (H\&E)-stained tissue sections collected from the early time points (e.g., 18-24 hr) indicated that there was pronounced mucosal damage in ricin-treated WT and IE-Cpr-null mice that included widespread villus atrophy, swelling of interepithelial space and separation of the epithelium from the lamina propria (Figures 1A-D; S1). In general, IE-Cpr-null mice appeared more affected than toxin- treated control animals at early time points, although these differences did not achieve statistical significance. However, at $36 \mathrm{hr}$ post ricin challenge, there was clearly a difference between IE-Cpr-null mice and WT littermates. The intestinal epithelium of toxin-treated WT mice had returned to baseline levels and appeared indistinguishable from vehicle (i.e., PBS) treated mice (Figure 1E). In contrast, in the intestinal mucosa of IE-Cpr-null mice there was significant toxin-induced tissue damage (Figure 1E). These data suggest that the IE-Cpr-null mice may not be more sensitive to the initial toxin exposure as compared to control mice, but may in fact have defects in epithelial restitution and/or repair.

We have previously shown that local levels of the pro-inflammatory chemokine MCP-1 correlate with the severity of ricin-induced epithelial damage ${ }^{18}$. We therefore measured MCP-1 levels in WT and IE-Cpr-null mice as a quantitative measure of toxin-induced damage. As expected, MCP-1 levels spiked at 12 and $18 \mathrm{hr}$ after ricin challenge in WT and IE-Cpr-null mice (Figure 1F; S2). In WT mice, MCP-1 levels in toxin-treated mice returned to baseline by $36 \mathrm{hr}$, whereas they remained significantly elevated in the corresponding IE-Cpr-null mice (Figure 1F). By $60 \mathrm{hr}$ post toxin challenge, MCP-1 levels had returned to normal in both WT and knockout mice. These results are consistent with the IE-Cpr-null mice having defects in epithelial and/or mucosal restitution following acute toxin exposure.

We postulated that IE-Cpr-null mice may be altered in various aspects of epithelial barrier function and/or have altered immune physiology, which may account for their differential susceptibility to ricin. To examine intestinal permeability, we assessed fecal pellets for the presence of elevated levels of serum proteins, albumin and IgG. Levels of serum albumin and IgG in fecal extracts are known to increase in animals in which the integrity of the intestinal barrier is compromised ${ }^{21}$. We found that neither albumin nor IgG levels were elevated in IE-Cpr-null mice as compared to age-matched WT mice (Figure 2). In fact, albumin levels were slightly lower $(p<0.0001)$ in the IE-Cpr-null mice as compared to age-matched WT mice, demonstrating that at steady state the integrity of the intestinal epithelium of IE-Cpr-null mice is not compromised.

Fecal (but not serum) IgA antibodies are elevated in IE-Cpr-null mice. We next measured total IgA levels in fecal pellets as a surrogate marker of the status of the mucosal immune system in IE-Cpr-null mice. IgA is the predominant antibody isotype in intestinal secretions and is produced in response to local microbial and antigenic stimulation ${ }^{22}$. We therefore examined IgA levels in fecal pellets of mice before or after treatment with the mucosal adjuvant cholera toxin (CT). CT does not induce epithelial damage in mice, but does elicit strong toxin-specific antibody and $\mathrm{T}$ cells responses ${ }^{23}$. Freshly voided fecal pellets from WT and IE-Cpr-null mice were collected over regular intervals before or every two weeks after treatment with CT and assayed for total IgA levels. We found that IE-Cpr-null mice consistently had significantly higher (2-8 fold) levels of IgA antibodies in fecal extracts as compared to agematched control mice (Figure 3A). IgA levels were elevated in the gut, but not in the systemic compartment, as serum IgA (and IgG) levels were comparable in IE-Cpr-null and WT control mice (Figure 3B, C). These data suggest that the IE-Cpr-null mice have a gut specific increase in intestinal IgA levels, possibly due to increases in antibody production and/or transport.

We reasoned that elevated levels of fecal IgA in IE-Cpr-null mice could be due to an increase in IgA transport by polymeric immunoglobulin receptor (pIgR), which is known to be the rate-limiting step in delivery of IgA into intestinal secretions ${ }^{22}$. To test this possibility we measured pIgR mRNA levels using real-time PCR in intestinal epithelial cells from age- and sex-matched WT and IE-Cpr-null mice. By this measure, we found no difference in pIgR expression between IE-Cpr-null and WT mice (Figure S3), indicating that enhanced IgA transport (based on changes in transcriptional regu- 

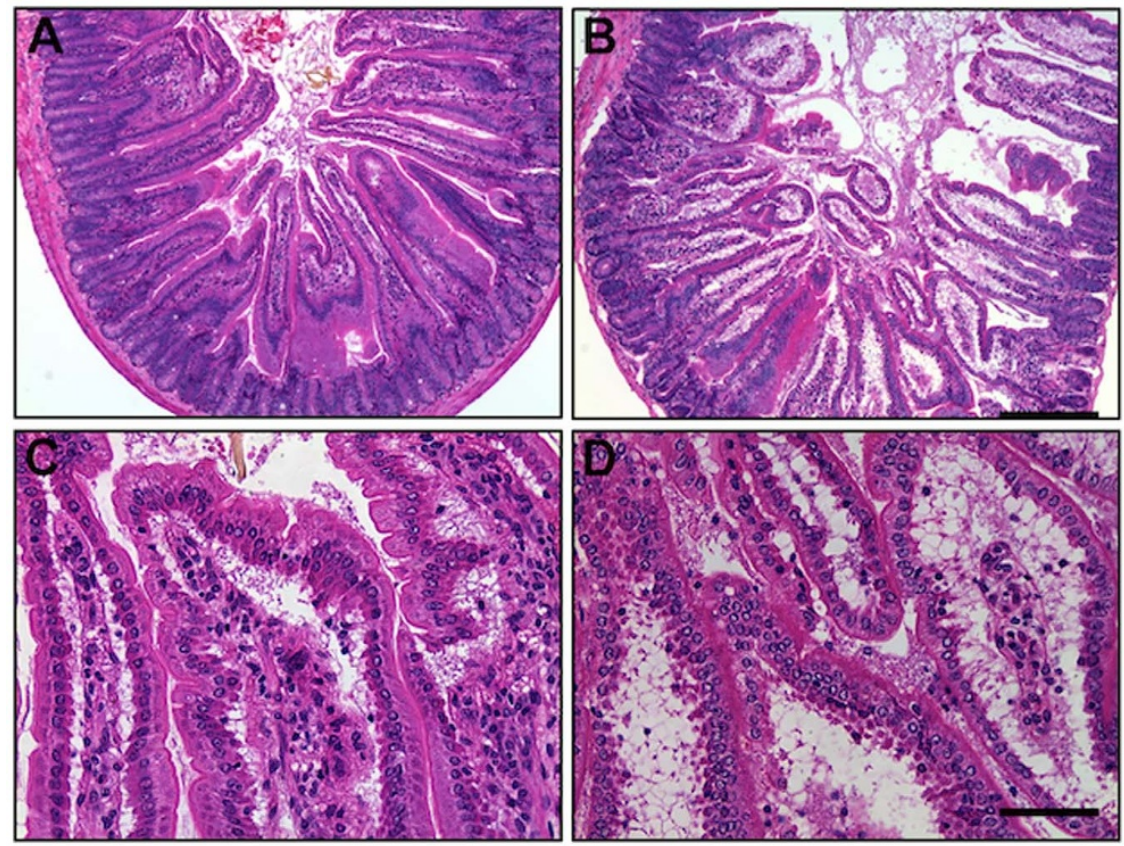

$E$
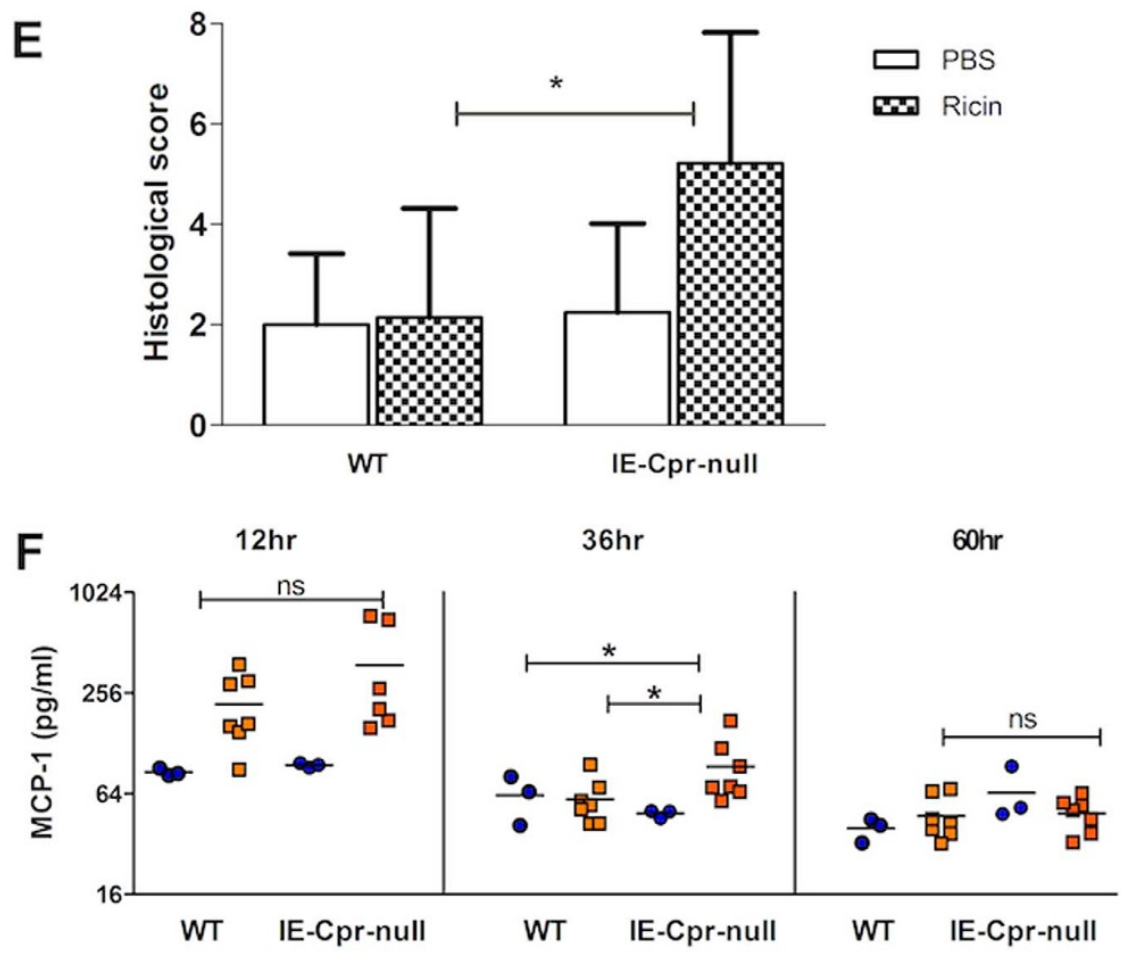

Figure 1 Intestinal lesions and inflammatory chemokine production in WT and IE-Cpr-null mice following ricin challenge. Intestinal tissues were collected from WT and IE-Cpr-null mice at time points after the animals had been gavaged with ricin toxin, as described in Methods.

(Panels A-D) Representative H\&E sections of proximal small intestines collected from WT (A, C) and IE-Cpr-null mice (B, D) 24 hr after ricin challenge. (Panel E) Histological scoring of tissues of WT and IE-Cpr-null mice collected $36 \mathrm{hr}$ after challenge demonstrating that knock-out mice have more profound tissue damage than control mice in response to ricin. (Panel F) MCP-1 levels in intestinal tissue homogenates of WT and IE-Cpr-null mice at indicated time points after ricin challenge. PBS control are indicated as solid blue circles; ricin challenged animals are solid orange squares. The asterisks indicate significance $(\mathrm{p}<0.05)$ as determined by the Students $t$ test.

lation of pIgR) is not likely to explain elevated levels of total IgA observed in the IE-Cpr-null mice.

Retinoic acid (RA) homeostasis and gut-associated lymphoid tissues (GALT) are not altered in the intestinal mucosa of IECpr-null mice. RA in the intestine and GALT can promote B cell class switching to IgA producing cells, and thus increase the production of IgA in the intestinal mucosa. Since P450 enzymes participate in both synthesis and degradation of $\mathrm{RA}^{24,25}$, we postulated that the loss of intestinal P450 activities in the IE-Cprnull mice could lead to altered levels of RA. However, the in vivo level of all-trans retinoic acid (atRA) in the small intestinal epithelium was not significantly different between WT and IE-Cpr-null mice (Figure S4). This is most likely because of contributions by non-P450 


\section{A. Albumin}

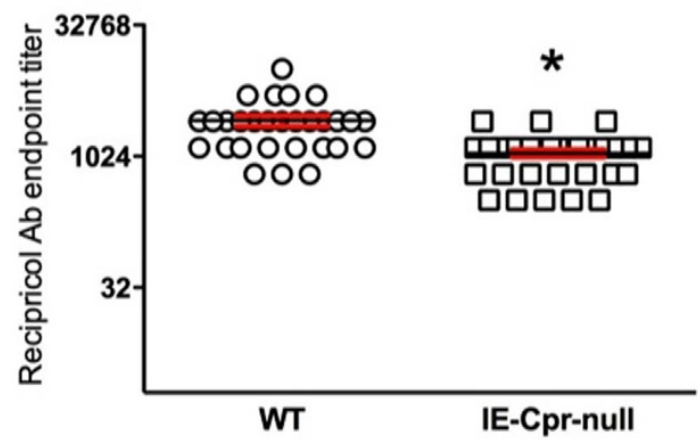

B. IgG

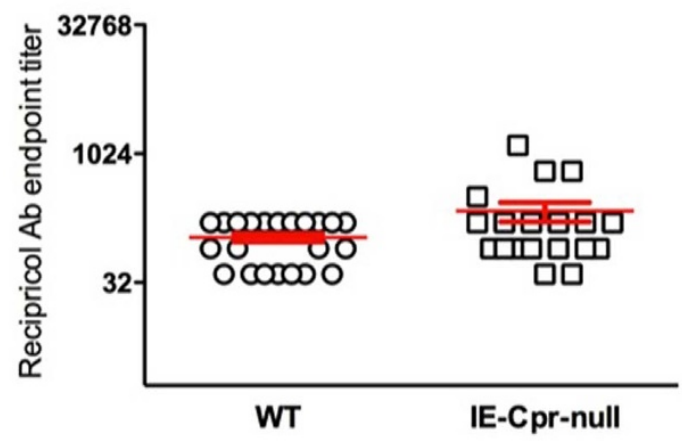

Figure $2 \mid$ Fecal albumin and IgG levels in WT and IE-Cpr-null mice. Freshly voided fecal pellets from WT and IE-Cpr-null mice were homogenized as indicated in the Methods. We used ELISAs to assess (Panel A) albumin and (Panel B) IgG levels in the homogenates. Each symbol represents a single fecal pellet collection. Statistical analysis was performed with the Mann-Whitney test $(\mathrm{n}=8)$. Red bars indicate average values \pm SEM. $*$, $\mathrm{P}<0.05$.

enzymes in RA synthesis, as well as parallel decreases in rates of degradation of atRA, which is mainly catalyzed by microsomal P450s, in the intestinal mucosa of IE-Cpr-null mice. Furthermore, these results suggest that the increase in fecal sIgA levels in the IECpr-null mice was unlikely due to an alteration in RA homeostasis.

Elevated levels of IgA could also be the consequence of dysregulation of GALT, particularly altered cellularity of intestinal Peyer's patches. Peyer's patches collected from IE-Cpr-null and WT mice were stained with $\mathrm{H} \& \mathrm{E}$ and observed by bright-field microscopy or prepared as cryosection and stained for markers of $\mathrm{B}$ cells, $\mathrm{T}$ cells and dendritic cells. We found that the overall structure of the Peyer's patches in IE-Cpr-null mice was by all measures identical to that of WT mice. The Peyer's patch lymphoid follicles were normal in size, number and cellular organization (Figures 4; S4; S5). Quantitative analysis of B and T cell numbers by flow cytometry further confirmed that IE-Cpr-null mice have normal Peyer's patch composition. These results indicate that the increase in fecal $\operatorname{sg} \mathrm{A}$ levels was not due to a gross alteration in the GALT, although they do not exclude the possibility that more subtle differences may exist between WT and IE-Cpr-null mice that ultimately influence IgA production and or transport.

Serum and small intestinal tissue levels of corticosterone are not altered in the IE-Cpr-null mice. Considering the anti-inflammatory properties of glucocorticoids and the involvement of P450s in their biosynthesis, we postulated that the observed differences in sensitivity between WT and IE-Cpr-null mice to ricin challenge could be a consequence of differences in serum and/or tissue glucocorticoid levels. We therefore examined glucocorticoid levels in WT and IE-Cpr-null mice before and after ricin challenge. Among the four glucocorticoids analyzed (corticosterone, cortisol, deoxycorticosterone, and 11-deoxycortisol), only corticosterone was detectable in serum and small intestinal epithelium. We found that there were no differences between WT and IE-Cpr-null mice in the basal corticosterone levels in either sera or small intestinal epithelium, or in the levels at $16 \mathrm{~h}$ and $39 \mathrm{~h}$ after ricin challenge (Figure 5). This result suggests that the differing sensitivity of the two strains to ricin-induced toxicity was not due to a difference in serum or tissue glucocorticoid levels.

Levels of 11,12-DiHETE and 14,15-DiHETE are decreased in the small intestinal epithelium, but not in serum, of the IE-Cpr-null mice. P450s also mediate one of the three major pathways of arachidonic acid (AA) metabolism, producing hydroxyeicosatrienoic acids (HETES) and epoxyeicosatrienoic acids (EETs). EETs, which are readily converted to dihydroxyeicosatrienoic acids ( $\mathrm{DiH}-$ ETEs) by epoxide hydrolases, are well-known anti-inflammatory mediators ${ }^{26-28}$. In in vitro studies, we detected a number of AA metabolites in small intestinal microsomal reactions with AA, including 5,6-EET, 8,9-EET, 11,12-EET, 14,15-EET, 5,6-DiHETE, 8,9DiHETE, 11,12-DiHETE,14,15-DiHETE, 19-HETE and 20-HETE, of which 11,12-DiHETE and 14,15-DiHETE appeared to be the most abundant (data not shown); the rates of metabolite formation were substantially lower in IE-Cpr-null mice than in WT mice, thus confirming role of microsomal P450 enzymes in intestinal AA metabolism. However, under the assay conditions used, we could reliably detect only 11,12-DiHETE and 14,15-DiHETE, as well as $\mathrm{AA}$, but not the other aforementioned in vitro metabolites, in the serum and small intestinal epithelium of either WT or IE-Cpr-null mice. The levels of 11,12-DiHETE and 14,15-DiHETE were significantly lower in the intestinal epithelium of IE-Cpr-null mice as compared to age and sex-matched WT mice, whereas AA levels were not significantly different between the two mouse strains (Figure 6A). In the serum, levels of AA and the two detected DiHETEs were not significantly different between WT and IECpr-null mice (Figure 6B). These results indicate that the loss of intestinal P450 activities did not affect systemic levels of AA and its metabolites, but led to selective reduction in intestinal levels of 11,12-DiHETE and 14,15-DiHETE (and presumably, their corresponding, less stable EET precursors).

\section{Discussion}

In this study we took advantage of the recently developed IE-Cprnull mouse model to investigate the role of epithelial P450 enzymes in modulating intestinal inflammation and immunity following exposure to ricin toxin. Our data suggest that at steady state, in a specific pathogen-free (SPF) environment, IE-Cpr-null mice display no obvious alterations in intestinal epithelial barrier function, nor do they have any gross alterations in the GALT. Moreover, the IE-Cprnull mice were fully capable of mounting both local and systemic antibody responses to $\mathrm{CT}$ administrated by gavage. However, the knock-out mice were more sensitive than WT littermate controls to ricin toxin challenge, as evidenced by increased severity of mucosal damage and elevated levels of the pro-inflammatory chemokine MCP-1. While we have yet to elucidate the underlying mechanisms responsible for increased sensitivity of the IE-Cpr-null mice to ricininduced tissue damage and inflammation, our study suggests that the P450-mediated metabolism of endogenous substrates, such as AA, could play a role in this process.

The increased severity of tissue damage associated with the IECpr-null mice following ricin exposure could be a consequence of the CPR-deficient epithelial cells being intrinsically less resistant to the effects of toxins and/or impaired in one or more steps associated with epithelial restitution following toxic insult ${ }^{29}$. Our results implicate epithelial restitution and/or renewal as likely being affected in the IE- 


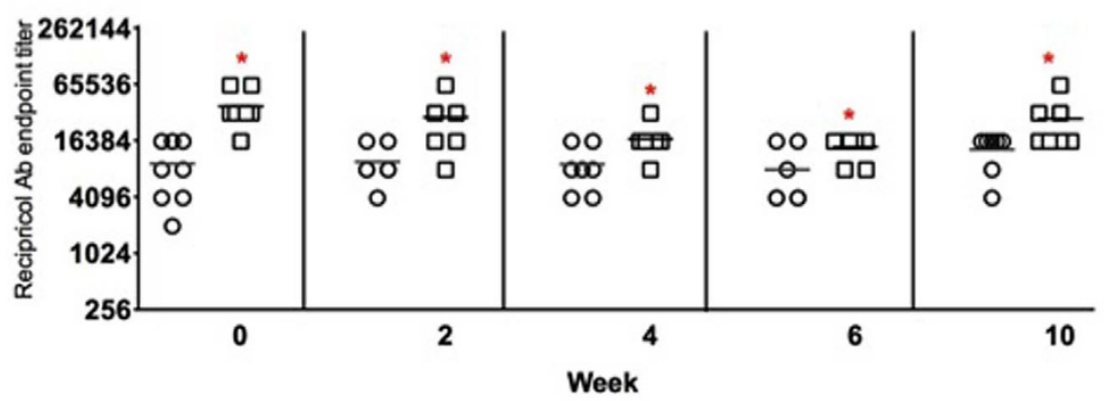

B. Serum IgG

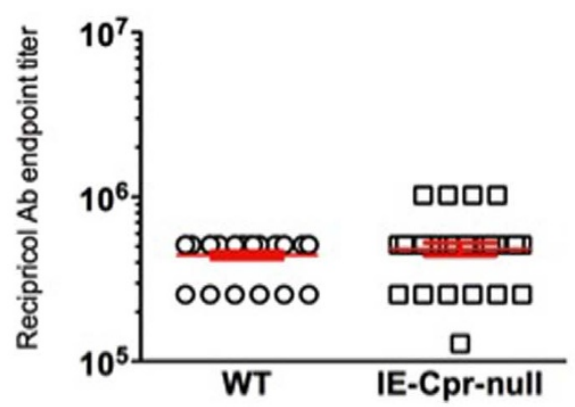

C. Serum IgA

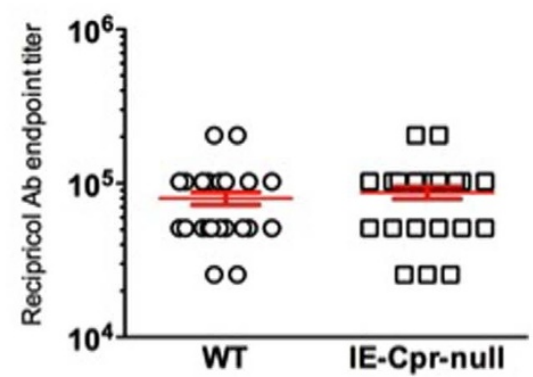

Figure 3 Total Fecal and serum antibody levels in WT and IE-Cpr-null mice before or after mucosal adjuvant treatment. (Panel A) Fecal pellets samples were collected from individual mice at two week intervals for ten weeks from groups $(\mathrm{n}=8)$ of WT and IE-Cpr-null mice repeatedly immunized with CT, as described in Methods. IgA levels in fecal extracts were measured with ELISA. Horizontal bars indicate averages. (Panels B and C) Baseline serum IgG (B) and IgA (C) levels were measured from groups of age matched WT and IE-Cpr-null mice. Each symbol represents a single mouse. Red bars in Panels B and C indicate average values \pm SEM. Statistical analysis was performed with Mann-Whitney T-test $(*, P<0.05$, and $* *, P<0.005)$.

Cpr-null mice, and not the intrinsic integrity of the intestinal epithelium. Ricin toxin is a member of the ribosome-inactivating protein (RIP) family of toxins that are known to have multiple effects on intestinal epithelial cells. In vitro, application of ricin to the apical surfaces of polarized intestinal epithelial cell monolayers results in an arrest of protein synthesis within 3-4 $\mathrm{hrs}^{30,31}$. One consequence of protein synthesis arrest is activation of the so-called ribotoxic stress response (RSR), which triggers cellular stress-activated protein kinase pathways (SAPKs) in intestinal epithelial cells, resulting in gross changes in gene expression and the secretion of an array of proinflammatory cytokines and chemokines ${ }^{32-36}$. Ricin, which is known to traffic retrograde to the endoplasmic reticulum (ER) may also affect physiology of the ER and thereby indirectly perturb microsomal enzymes, including CYPs ${ }^{37}$. The effects of ricin on the intestinal epithelium are complicated in vivo, however, as we postulate that inflammatory cytokine secretion by lamina propria macrophages exacerbates and accelerates toxin-induced epithelial cell death ${ }^{38}$.

It is worth noting that MHC II gene expression is upregulated in intestinal epithelial cells of IE-Cpr-null mice ${ }^{15}$. MHC II plays an essential role in the adaptive immunity through antigen presentation to $\mathrm{CD}^{+} \mathrm{T}$ cells. The IE cells are capable of processing and presenting gut luminal antigens to $\mathrm{CD}^{+} \mathrm{T}$ cells within the intestinal mucosa ${ }^{39}$. However, further studies are needed to determine whether the upregulation of the MHC II genes was mechanistically related to the observed hypersensitivity to ricin toxicity in the IE-Cpr-null mice. In that regard, it was recently reported that induction of IE cell MHC II expression underlies the anti-inflammatory function of IFN- $\gamma$ in the mouse intestine ${ }^{40}$, a finding in contrast to the present observation of an apparent association of increased IE cell MHC II expression with increased sensitivity to ricin-induced intestinal inflammation. In our study, we also found that the Peyer's patch lymphoid follicles in IECpr-null mice were normal in size, number and cellular organization, and that there was no difference in total $\mathrm{B}$ cell and $\mathrm{T}$ cell numbers between WT and IE-Cpr-null mice, results suggesting that the greater expression of IE cell MHC II genes in the IE-Cpr-null mice was not associated with any gross alterations in the gut immune system. It remains to be determined whether the chronic elevation of IE cell MHC II gene expression is associated with subtle differences between the two mouse strains in T-cell activation in the intestine.

SIgA is the most abundant immunoglobulin class in the GI tract and mediates a diverse array of functions associated with intestinal immunity ${ }^{41-43}$. IgA-producing B cells arise in Peyer's patches in response to mucosal antigens and then migrate into the surrounding mucosa and mature into plasma cells. Dimeric and polymeric forms of IgA present in interstitial fluids are transported unidirectionally into the intestinal lumen by the pIgR, ultimately giving rise to SIgA. It is interesting therefore that steady-state levels of intestinal IgA were markedly elevated in IE-Cpr-null mice as compared to WT control animals. The fact that serum IgA levels were unchanged in IE-Cprnull indicates that the absence of intestinal P450 enzyme activities results in a local (and not systemic) effect on antibody levels. Our studies suggest that the observed increase in fecal IgA levels was not due to alterations in mucosal B cell numbers or an up-regulation of the pIgR gene expression. We did not, however, examine the effect of the IE CPR mutation on pIgR transport activity. Transcytosis of IgA by the pIgR is influenced by environmental factors and controlled at the post-transcriptional level by SRC family of protein tyrosine kinases $^{44}$, raising the possibility that there is a link between cytochrome P450 enzymes and pIgR transport activity. Addressing this issue will require the use of well-characterized model of polarized intestinal epithelial cell monolayers in which pIgR transport has been reconstituted ${ }^{45}$.

It remains to be determined whether the reduction in intestinal levels of 11,12-DiHETE and 14,15-DiHETE (and presumably, their 

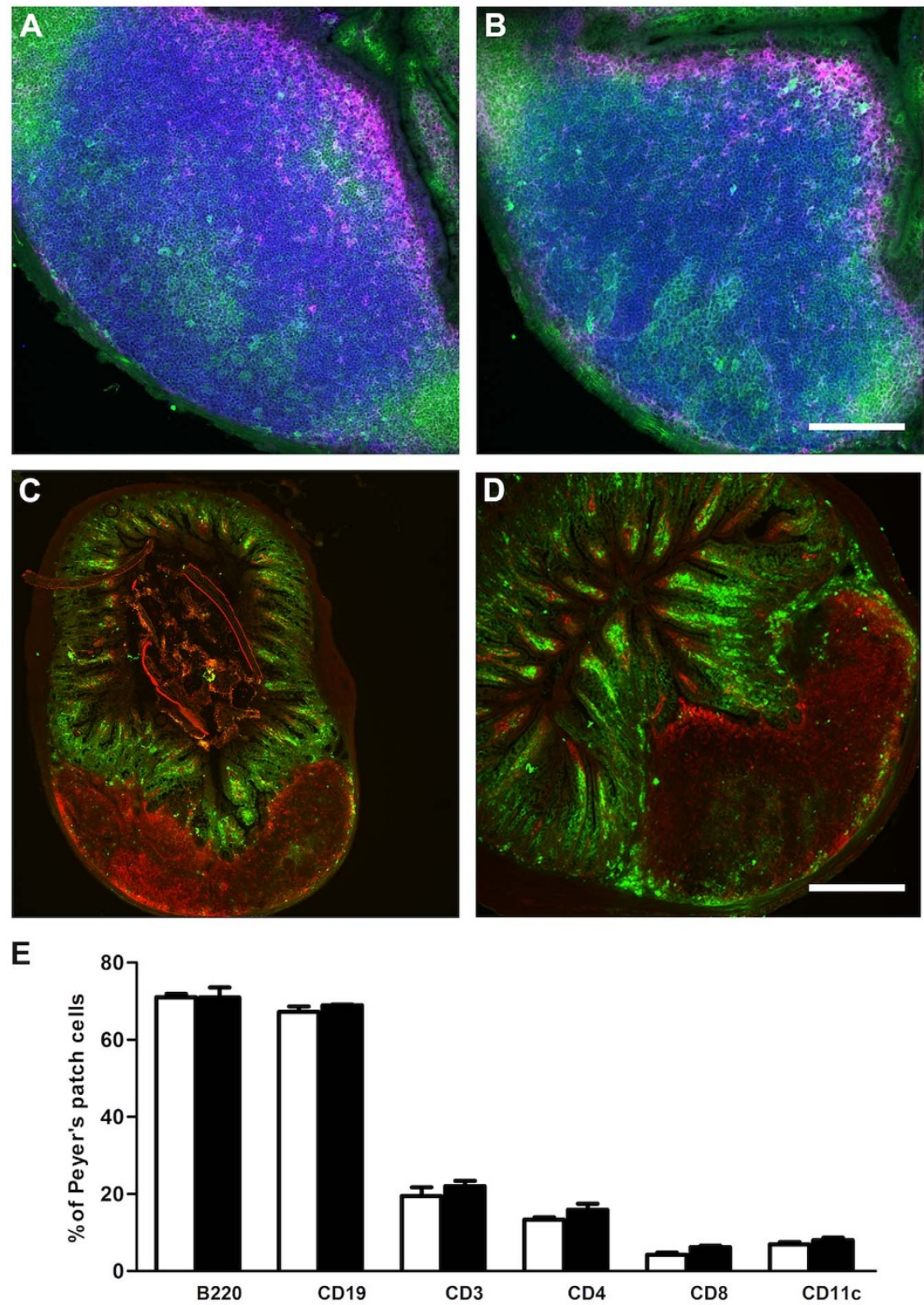

Figure $4 \mid$ Cellularity of Peyer's patches from WT and IE-Cpr-null mice. Peyer's patches from 8 wk-old WT (Panels A, C) and IE-Cpr-null (Panels B, D) mice were prepared and immuno-stained as described in the Methods. Cryosections were labeled with fluorophore-conjugated antibodies as indicated below. (Panels A, B) Cryosections were stained with antibodies against CD11c (magenta), B220 (blue), and CD3 (green). (Panels C, D) Cryosections were stained with antibodies against IgA (green) and CD11c (red). (Panel E) Monodisperse cell suspensions of total Peyer's patch cells from WT (open bars) and IE-Cpr-null (solid bars)mice were subjected to flow cytometry as a means to enumerate B and T cell subsets. Cell suspensions were labeled with fluorophore-conjugated antibodies against epitopes B220, CD19, CD3, CD4, or CD8. At least four mice were used for each analysis and the experiments were repeated at least three times.

corresponding EET precursors) would explain, at least in part, why the IE-Cpr-null mice had increased sensitivity to ricin-induced inflammation in the small intestine. EETs have been shown to have a number of anti-inflammatory effects ${ }^{27}$. EETs, formed mainly by CYP2C- and CYP2J-mediated AA metabolism, elicit anti-inflammation effects by suppressing cytokine-induced expression of endothelial cell adhesion molecules, and by inhibiting the activation of NF-kB, a key transcription factor for the induction of many proinflammatory genes ${ }^{26,27}$. In addition, EETs can promote organ and tissue regeneration, as evidenced by delayed tissue regeneration after genetically or pharmacologically lowering the levels of EETs, and accelerated organ regeneration after administration of inhibitors of soluble epoxide hydrolase, which elevate endogenous EETs levels ${ }^{46}$. Therefore, a decrease in the levels of intestinal EETs, as we deduce to occur in the IE-Cpr-null mice, might delay epithelial recovery following the injury induced by ricin exposure.

It should be noted that the tissue-specific loss of CPR in the intestinal epithelium results in the loss of not only microsomal P450 activities, but also heme oxygenase (HO) activities in the epithelial cells ${ }^{15}$. Thus, loss of the epithelial $\mathrm{HO}$ activity might also contribute to the mechanisms for the increased sensitivity of IE-Cpr-null mice to ricin-induced small intestinal tissue damage. $\mathrm{HO}$ is a rate-limiting enzyme in the breakdown of heme. It is believed that HO, possibly through its metabolite bilirubin, has a protective role against intestinal inflammation and oxidative stress ${ }^{47,48}$. However, although $\mathrm{HO}$ activity in the epithelial cells was decreased by more than $90 \%$ in IECpr-null mice as compared to WT mice, there was no significant difference between WT and IE-Cpr-null mice in heme and bilirubin 
60

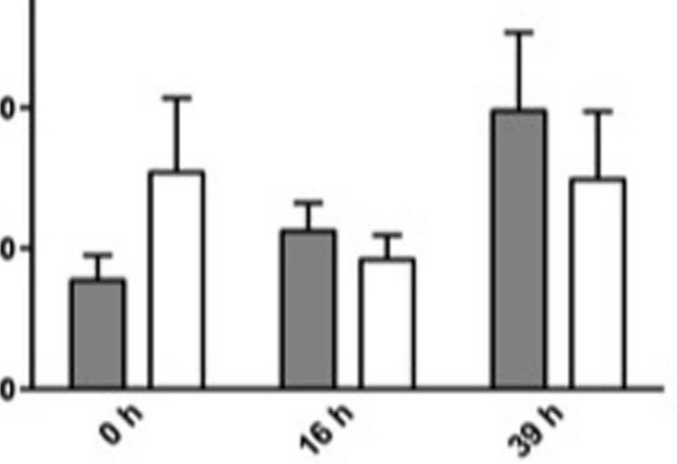

\section{B. Serum}

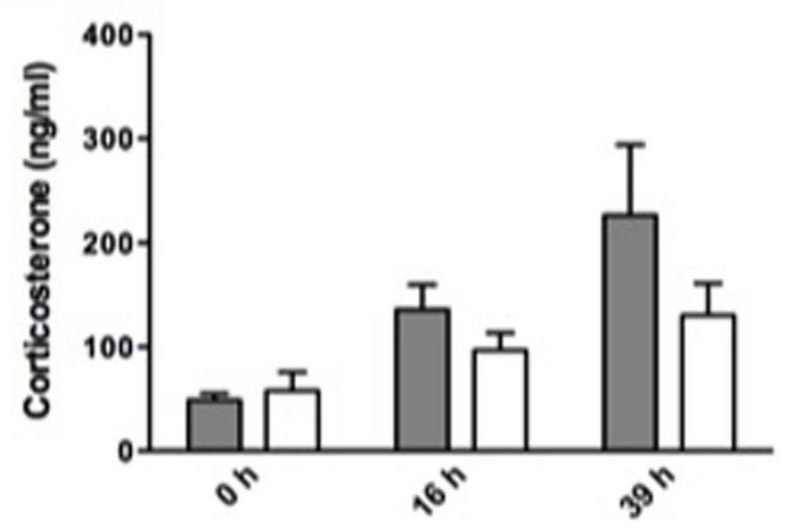

Figure $5 \mid$ Corticosterone levels in WT and IE-Cpr-null mice. Serum and small intestinal mucosa were collected from $2 \sim 3$-month old, female mice (either untreated or at $16 \mathrm{~h}$ or $39 \mathrm{~h}$ after ricin challenge). Samples were processed individually to measure corticosterone levels with LC-MS/MS, as described in Methods. Data represent means \pm SEM $(n=5-12)$.

levels in intestinal epithelial cells (15). Therefore, it appears that HO activity in the epithelial cells does not play an essential role in controlling bilirubin levels, a notion arguing against a role for the loss of $\mathrm{HO}$ in the increased sensitivity to ricin. Nevertheless, further studies to directly address the role of $\mathrm{HO}$ are warranted. It is also intriguing that the IE-Cpr-null mice were hyperresponsive to some challenges (ricin and CT) but not to others (bacterial infection). Further studies on metabolomic differences between the null and WT mice, particularly for endogenous compounds that may differentially modulate immune responses to differing types of pathogens, may shed light on the underlying mechanisms.

\section{Methods}

Chemicals and reagents. Ricin toxin was purchased from Vector Laboratories (Burlingame, CA). Tween 20 was purchased from Bio-Rad (Torrance, CA). Paraformaldehyde (16\%) solution was purchased from Electron Microscopy Sciences (Fort Washington, PA) and diluted 1:4 into phosphate-buffered saline (PBS) or in PHEM buffer prior to use. The steroids were purchased from Steraloids (Newport, RI). Arachidonic acid and its metabolites were purchased from Cayman Chemical (Ann Arbor, MI). All other chemicals were obtained from the Sigma-Aldrich Company (St. Louis, MO), unless noted otherwise. High-performance liquid chromatography (HPLC)-grade acetonitrile, methanol, and water were from Fisher Scientific (Pittsburgh, PA).

Animals and treatments. Experiments described in this study that involve mice were approved by and performed in strict accordance with the Wadsworth Center's Institutional Animal Care and Use Committee (IACUC) under protocols 11-331 and 12-428 and 13-384. The Wadsworth Center complies with the Public Health Service Policy on Humane Care and Use of Laboratory Animals and was issues assurance number A3183-01. Moreover, the Wadsworth Center is fully accredited by the Association for Assessment and Accreditation of Laboratory Animal Care (AAALAC). Obtaining this voluntary accreditation status reflects that Wadsworth Center's Animal Care and Use Program meets all of the standards required by law, and goes beyond the standards as it strives to achieve excellence in animal care and use.

Adult male and female IE-Cpr-null mice (2- to 3-month-old) and age matched WT littermates were obtained from breeding stocks maintained at the Wadsworth Center under SPF conditions. The IE-Cpr-null mice are congenic to C57BL/6, as described previously ${ }^{11}$. Mice were housed under conventional, specific pathogen-free conditions. Animals were provided food and water ad libitum. Mice were euthanized by $\mathrm{CO}_{2}$ asphyxiation followed by cervical dislocation, except for corticosterone determinations, in which the animals were sacrificed directly by cervical dislocation. Blood samples were collected by cardiac puncture and were kept on ice for $1 \mathrm{~h}$ prior to centrifugation at $13,000 \times g$ for $10 \mathrm{~min}$ at $4^{\circ} \mathrm{C}$. Small intestinal epithelial cells were isolated by scraping, as described previously ${ }^{49}$. Mice were administered with ricin toxin $(5-10 \mathrm{mg} / \mathrm{kg})$ or $S$. Typhimurium strain ATCC $14028 \mathrm{~S}\left(1 \times 10^{\wedge} 8-1 \times\right.$ $10^{\wedge} 10 \mathrm{CFU}$ ) by the intragastric route (i.g.) using feeding needles ${ }^{18}$. Freshly voided fecal pellets were collected as previously described ${ }^{38}$.

RNA isolation and pIgR qPCR analysis. Small intestinal epithelial cells of IE-Cprnull and WT mice (4-7 for each group) were collected for RNA preparation essentially as described ${ }^{15}$. Total RNA was prepared from enterocytes of individual mice, using TRIzol (Invitrogen, Carlsbad, CA). RNA concentration and purity were determined spectrally, and the integrity of the RNA samples was assessed by ethidium bromide staining after agarose gel electrophoresis. Real-time PCR was performed using $2 \mu \mathrm{g}$ of total RNA as described ${ }^{15}$. PCR primers were the same as previously reported ${ }^{50}$ (forward: $5^{\prime}$-agtaaccgaggcctgtcctt- $3^{\prime}$, and reverse, $5^{\prime}$-gtcactcggcaactcagga$\left.3^{\prime}\right)$. The levels of mRNAs in various total RNA preparations were normalized by the level of GAPDH mRNA in a given sample.

Measurement of retinoic acid (RA) levels in small intestinal epithelium. RA extraction was performed essentially as described previously ${ }^{51}$. Briefly, small intestinal mucosa from each mouse was homogenized in 3 volumes of saline; a $0.45-$ $\mathrm{ml}$ aliquot of the homogenate was spiked with $10 \mu \mathrm{l}$ of the internal standard (d5atRA, $2 \mathrm{ng} / \mu \mathrm{l}$ ) and then extracted with hexane according to a 2 -step protocol ${ }^{51}$. The organic phase from step two were dried under nitrogen and then resuspended in $60 \mu \mathrm{l}$ of acetonitrile and analyzed with LC-MS/MS (ESI negative ionization mode).

For RA detection a Symmetry $\mathrm{C}_{18}$ column $(2.1 \times 150 \mathrm{~mm}, 3.5 \mu \mathrm{m}$ particle size, Waters, Milford, MA, USA) was used for HPLC. The mobile phase consisted of $2 \mathrm{mM}$ ammonium acetate, $\mathrm{pH} 8.0(\mathrm{~A})$ and $10 \% 10 \mathrm{mM}$ ammonium acetate $/ 90 \%$ acetonitrile (B). A linear gradient was used, with the initial hold at $65 \% \mathrm{~B}$ for $2 \mathrm{~min}$, increasing to $90 \%$ B over $10 \mathrm{~min}$, a hold at $90 \% \mathrm{~B}$ for $10 \mathrm{~min}$, and a return to $65 \% \mathrm{~B}$ over $1 \mathrm{~min}$. The column was equilibrated at the initial condition for $12 \mathrm{~min}$ prior to the next injection. The flow rate was $0.25 \mathrm{ml} / \mathrm{min}$ throughout, and the mass spectrometer was operated in the ESI negative ionization mode. Nitrogen was used as the curtain gas ( $30 \mathrm{psi}$ ), gas 1 (60 psi), gas 2 (60 psi), and the collision gas (setting high). The ion spray voltage was set at $-4500 \mathrm{~V}$, and the gas temperature was at $400^{\circ} \mathrm{C}$. The declustering and entrance potentials were -80 and $-8 \mathrm{~V}$, respectively. The collision energy was $-30 \mathrm{eV}$ and collision cell exit potential was $-6 \mathrm{~V}$.

Measurement of corticosterone and eicosanoids in serum and intestinal epithelium. Small intestinal mucosa was homogenized in 3 volumes of methanol/ water (2:1); 1-ml aliquot of the homogenate was spiked with $10 \mu \mathrm{l}$ of an internal standard $\left({ }^{13} \mathrm{C} 2\right.$-progesterone, $15.8 \mu \mathrm{M}$; d8-AA $10 \mathrm{ng} / \mu \mathrm{L}$; or d8-AEA, $\left.2 \mathrm{ng} / \mu \mathrm{L}\right)$, and centrifuged at $20,000 \times \mathrm{g}$ for $10 \mathrm{~min}$. The supernatant was collected and diluted with $2 \mathrm{ml}$ of $\mathrm{H}_{2} \mathrm{O}$, and then purified by solid-phase extraction (SPE) on Isolute $\mathrm{C}_{18}$ cartridges $(200 \mathrm{mg} / 3 \mathrm{ml}$, Biotage, Charlottesville, VA, USA). For serum, $50 \mu \mathrm{l}$ was spiked with the internal standards, and $300 \mu \mathrm{l}$ of methanol was added to precipitate proteins, followed by centrifugation at $20,000 \times \mathrm{g}$ for $10 \mathrm{~min}$. The supernatant was collected and diluted by $1.6 \mathrm{ml}$ of $\mathrm{H}_{2} \mathrm{O}$ prior to SPE. The $\mathrm{C}_{18}$ cartridges were equilibrated with $\mathrm{H}_{2} \mathrm{O}$ prior to loading of the diluted samples, and the analytes were eluted in $1 \mathrm{ml}$ of methanol followed by $1 \mathrm{ml}$ of methylene chloride. The combined eluate was evaporated to dryness under $\mathrm{N}_{2}$. The residues were resuspended in $100 \mu \mathrm{l}$ of methanol. The processed samples were analyzed by the established LC-MS/MS (APCI positive mode for glucocorticoids, and ESI negative mode for AA and its metabolites) methods ${ }^{52-54}$.

Glucocorticoids were determined essentially according to ${ }^{52}$ using a Luna PhenylHexyl column $(2.0 \times 150 \mathrm{~mm}, 3 \mu \mathrm{m}$ particle size, Phenomenex, Torrance, CA, USA for HPLC. The mobile phase consisted of $0.1 \%$ formic acid in water (A) and $0.1 \%$ formic acid in acetonitrile (B). A linear gradient was used, with the initial hold at 30\% B for $2 \mathrm{~min}$, increasing to $90 \%$ B over $10 \mathrm{~min}$, then increasing to $100 \%$ B in $3 \mathrm{~min}$, a hold at $100 \%$ B for $5 \mathrm{~min}$, and a return to $30 \%$ B over $1 \mathrm{~min}$. The column was equilibrated at the initial condition for $10 \mathrm{~min}$ prior to the next injection. The flow rate was $0.3 \mathrm{ml} / \mathrm{min}$ throughout. Nitrogen was used as the curtain gas ( $30 \mathrm{psi}$ ), gas 1 and 2 (50 psi), and the collision gas (setting medium). The nebulizer current was $3 \mu \mathrm{A}$, and the gas temperature was $500^{\circ} \mathrm{C}$. The declustering and entrance potentials were 85 and $10 \mathrm{~V}$, respectively. The collision energy was $32 \mathrm{eV}$ and collision cell exit potential was $15 \mathrm{~V}$.

All samples were analyzed on an Applied Biosystems/MDS Sciex API 4000 Q-Trap mass spectrometer equipped with a turbo ion spray source and interfaced with an Agilent 1200 series liquid chromatograph. For all samples, the injection volume was 

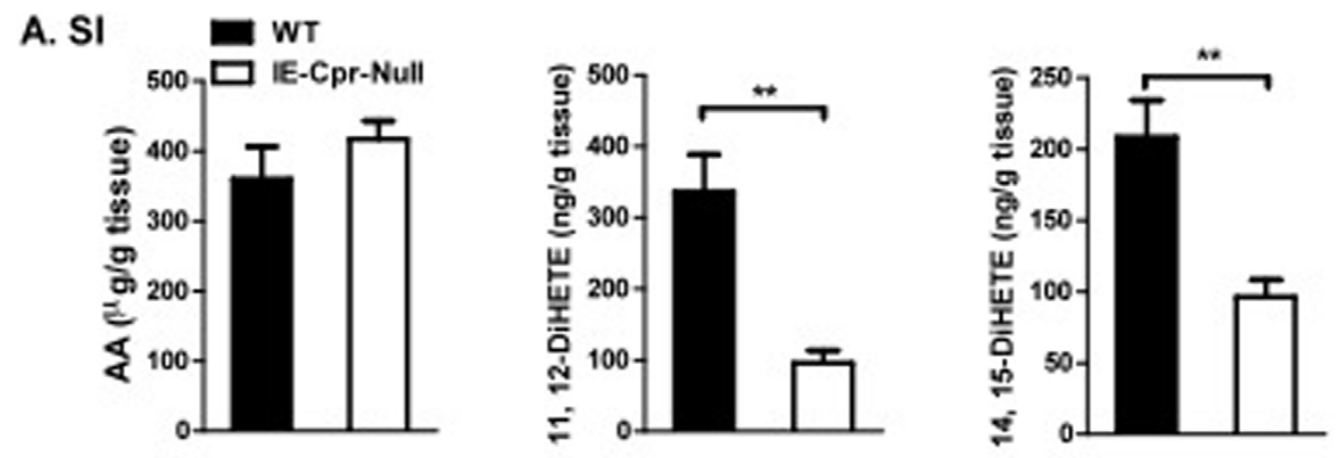

\section{B. Serum}
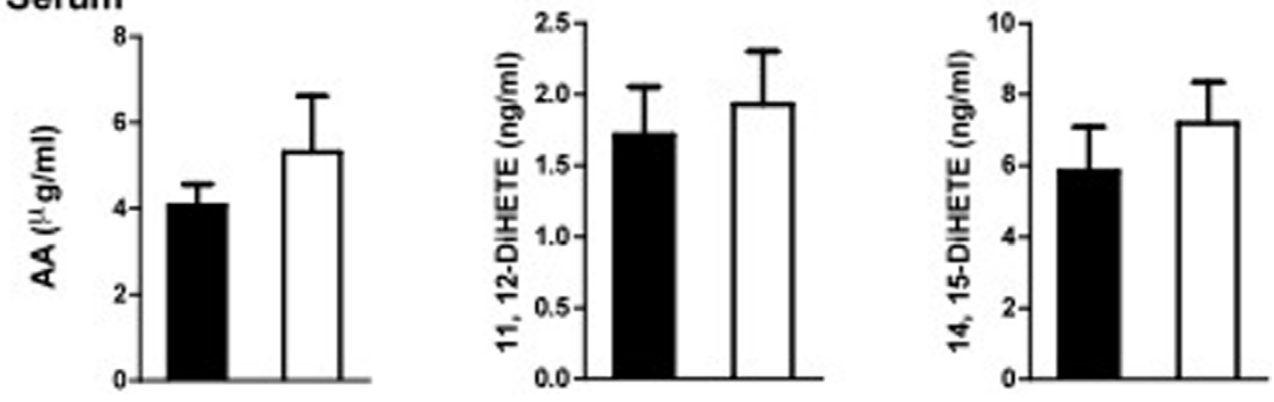

Figure 6 Levels of AA and its metabolites in small intestinal mucosa and serum of WT and IE-Cpr-null mice. Small intestinal mucosa and serum were collected from individual untreated (2 3-month old) WT and IE-Cpr-null female mice. Samples were processed to measure AA and its metabolites with LC-MS/MS, as described in Methods. Data represent means \pm SEM. ${ }^{* *}, \mathrm{P}<0.01$ compared to WT (Student's t test, $\mathrm{n}=8-11$ ).

set at $20 \mu \mathrm{l}$, and the column was at ambient temperature. Multiple reactions monitoring (MRM) was used for quantitative analysis. The MRM transitions for the analytes are given in Table 1 , which were based on previously reports ${ }^{52,54}$, and on product-ion spectrum of the standards (data not shown).

ELISA. Serum and fecal antibody titers were determined by ELISA, as described previously $^{38}$. Briefly Nunc Maxisorb F96 microtiter plates (Fisher) were coated with anti-IgA, anti-IgG, or anti-albumin antibodies $(0.1 \mu \mathrm{g} /$ well) in PBS ( $\mathrm{pH} 7.4)$ overnight at $4{ }^{\circ} \mathrm{C}$, washed three times with PBS-Tween 20 (PBS-T; 0.05\%, vol/vol), and blocked with goat serum ( $2 \%$, wt/vol, in PBS-T) for $1 \mathrm{~h}$, before being probed with primary Abs. Primary Abs were detected using horseradish peroxidase (HRP)-labeled goat anti-mouse IgA or IgG-specific polyclonal secondary antibodies (Southern Biotech) and TMB (3,3',5,5' tetramethylbenzidine) colorimetric substrate (Kirkegaard \& Perry, Gaithersburg, MD). Microtiter plates were analyzed with a SpectroMax 250 microtiter spectrophotometer (Molecular Devices), interfaced with a personal computer running Softmax software. Averages and standard errors between replicate samples were calculated using Excel 2010 (Microsoft, Redmond, WA).

Intragastric ricin challenge and tissue collection. Toxin challenge studies required a one-time administration of ricin ( $5 \mathrm{mg} / \mathrm{kg}$ diluted in PBS) to mice by the i.g. route using a $22 \mathrm{G} \times 1.5$-inch blunt-end feeding needle (Popper Scientific, New Hyde Park, $\mathrm{NY})^{18,38}$. Animals were euthanized by $\mathrm{CO}_{2}$ asphyxiation at twelve, thirty-six, and sixty hour time point. Freshly excised segments of the proximal small intestines of the mice were immersed in Bouin's fixative and embedded in paraffin, or homogenized in icecold cell lysis buffer (Cell Signaling, Beverly, MA) supplemented with protease inhibitors, and then frozen at $-20^{\circ} \mathrm{C}$. MCP-1 levels in intestinal homogenates were determined by the BD cytometric bead array (CBA) flex set (BD Biosciences, San Jose, CA), as described previously ${ }^{18}$. Flow cytometric analysis was done using a FACS
Calibur in the Wadsworth Center Immunology Core. Hematoxylin and eosin (H\&E) stained sections of the small intestine were scored for ricin intoxication according to a 12-point histologic grading system, which was based on the severity and extent of alterations in villus shape (width and height), lamina propria edema, interepithelial swelling, and the presence of cellular infiltrate in the intestinal lumen ${ }^{18}$. Tissue section samples were coded and blinded prior to being provided to investigators for scoring.

Hematoxylin-eosin (H\&E) staining. Bouin fixed tissue were sectioned; dry sections were fixed in $10 \%$ buffered formalin (Starplex Scientific, Etobicoke, Ontario, Canada) for $30 \mathrm{sec}$ and washed in tap water three times. After washing with running tap water for $3 \mathrm{~min}$, the sections were stained with Mayer's Haemalaun (Merck, Darmstadt, Germany) for $10 \mathrm{~min}$. Following differentiation in freshly prepared $3.75 \% \mathrm{HCl}$ (in $70 \%$ ethanol), the sections were washed with running tap water for another $5 \mathrm{~min}$, dehydrated in $70 \%$ and $90 \%$ ethanol for $2 \mathrm{~min}$ each, stained with alcoholic eosin (containing $0.1 \%$ phloxine in $90 \%$ ethanol; Sigma-Aldrich, Steinheim, Germany) for 5 min, dehydrated in $100 \%$ ethanol and xylene and finally mounted in Entellan New (Merck, Darmstadt, Germany) mounting medium.

Immuno fluorescence and fluorescence microscopy analysis of mouse Peyer's patches. Freshly dissected PPs from different sections of the small intestine were embedded in TissueTek1-Optimal Cutting Temperature (OCT) compound (Sakura Finetek, Torrance, CA, USA) and then snap-frozen in liquid nitrogen ${ }^{55}$. Frozen blocks were sectioned at $20 \mu \mathrm{m}$ with a Reichert-Jung 2800 e Cryostat (Leica, Wetzlar,

Germany), air dried overnight and then subjected to $2 \mathrm{~min}$ in acetone, followed by 3 five-minute incubations in PBS-Tween 20 (PBS-T; $0.05 \%$, vol/vol) at $25^{\circ} \mathrm{C}$. Slides were wiped dry carefully and with an ImmEdge hydrophobic pen a circle was drawn around each section to contain reagents. Sections were blocked with $2 \%$ goat serum in PBS for $30 \mathrm{~min}$ at $37^{\circ} \mathrm{C}$ (Vector Labs, Burlingame, CA, H-4000). Slides were rinsed for

\begin{tabular}{|c|c|c|c|c|c|}
\hline RA & $299 \rightarrow 255$ & Cortisol & $363 \rightarrow 267$ & AA & $303 \rightarrow 259$ \\
\hline d5-RA & $304 \rightarrow 260$ & Deoxy-corticosterone & $331 \rightarrow 107$ & 11,12-DiHETE & $337 \rightarrow 167$ \\
\hline d5-RA & $304 \rightarrow 120$ & 11-deoxycortisol & $347 \rightarrow 109$ & 14,15-DiHETE & $337 \rightarrow 207$ \\
\hline Corticosterone & $347 \rightarrow 121$ & 11-deoxycortisol & $347 \rightarrow 97$ & d8-AA & $311 \rightarrow 267$ \\
\hline
\end{tabular}


$10 \mathrm{sec}$ in PBS-T and Fc receptors were then blocked for 10 min at $37^{\circ} \mathrm{C}$ (with supernatants from ATCC 2.4.G2 cells or commercial Fc Block Rat Anti-Mouse CD16/CD32, BD Biosciences, San Jose, CA). Sections were stained with antibody cocktail of CD45R/B220, CD3, CD11c (CD45R/B220-APC, cat 553092, BD Biosciences, 561798 CD3 FITC, CD11c-PE, 17-0114-82, eBioscience, San Diego, CA). All staining incubations were done at $37^{\circ} \mathrm{C}$ for $1 \mathrm{hr}$ in a moisture chamber. Sections were washed with PBS-T, in three 5-min incubations. Sections were incubated with $4 \%$ Paraformaldehyde for $4 \mathrm{~min}$ at room temperature followed with a PBS-T rinse for $1 \mathrm{~min}$. Slides were sealed with ProLong Gold antifade reagent (Invitrogen, Grand Island, NY). Confocal images were collected on a Leica SP5 confocal system using a $10 \times$ air objective (NA 0.4 ) and a $2 \times$ optical zoom (Leica, Wetzlar, Germany).

Isolation of PP cells and flow cytometry. Single cell suspensions of PP cells were isolated as described ${ }^{55}$. For flow cytometry, isolated cells were transferred to a 96 round-bottom well plate and subjected to centrifugation at $1000 \times \mathrm{g}$ for $5 \mathrm{~min}$. Fc receptors were blocked for 15 min with supernatants from the ATCC 2.4.G2 cell line before the addition of the primary antibody cocktail $(20 \mathrm{ug} / \mathrm{ml})$. Cells were incubated on ice for $30 \mathrm{~min}$ with continuous rocking and then washed and fixed in PHEM buffer containing $1 \%$ paraformaldehyde and subjected to flow cytometry using a FACS Calibur. Results were analyzed using Cell Quest Pro software version 5.2. For imaging flow cytometry was performed using the Image Stream (Amnis, Seattle WA) equipped with a $480-560$ laser. Cells $\left(1 \times 10^{6}\right)$ were prepared in $50 \mu \mathrm{l}$ of PHEM buffer containing 1\% paraformaldehyde. Anti-mouse Abs CD45R/B220-APC, CD3-FITC, CD4-PE, CD8-PE were purchased from BD Biosciences (Franklin Lakes, NJ); CD45R/B220-APC was from eBioscience and CD19-PercP was from BioLegend.

1. Daniel, H. Molecular and integrative physiology of intestinal peptide transport. Annu Rev Physiol 66, 361-384 (2004).

2. Marsh, M. N. Digestive-absorptive functions of the enterocyte. Ann R Coll Surg Engl 48, 356-368 (1971).

3. Simon, T. C., Roth, K. A. \& Gordon, J. I. Use of transgenic mice to map cis-acting elements in the liver fatty acid-binding protein gene (Fabpl) that regulate its cell lineage-specific, differentiation-dependent, and spatial patterns of expression in the gut epithelium and in the liver acinus. J Biol Chem 268, 18345-18358 (1993).

4. Bouhet, S. \& Oswald, I. P. The effects of mycotoxins, fungal food contaminants, on the intestinal epithelial cell-derived innate immune response. Vet Immunol Immunopathol 108, 199-209 (2005).

5. Goto, Y. \& Kiyono, H. Epithelial barrier: an interface for the cross-communication between gut flora and immune system. Immunol Rev 245, 147-163 (2012).

6. Mantis, N. J. \& Bry, L. [The Intestinal Epithelium: The Interface Between Host and Pathogen] Immunity Against Mucosal Pathogens [Vajdy, M. (ed.)] (Springer, New York, 2008).

7. Colgan, S. P. Lipid mediators in epithelial cell-cell interactions. Cell Mol Life Sci 59, 754-760 (2002).

8. Dwinell, M. B., Johanesen, P. A. \& Smith, J. M. Immunobiology of epithelial chemokines in the intestinal mucosa. Surgery 133, 601-607 (2003).

9. Kagnoff, M. F. Microbial-epithelial cell crosstalk during inflammation: the host response. Ann N Y Acad Sci 1072, 313-320 (2006).

10. Ding, X. \& Kaminsky, L. S. Human extrahepatic cytochromes P450: function in xenobiotic metabolism and tissue-selective chemical toxicity in the respiratory and gastrointestinal tracts. Annu Rev Pharmacol Toxicol 43, 149-173 (2003).

11. Zhang, Q. Y., Fang, C., Zhang, J., Dunbar, D., Kaminsky, L. \& Ding, X. An intestinal epithelium-specific cytochrome P450 (P450) reductase-knockout mouse model: direct evidence for a role of intestinal p450s in first-pass clearance of oral nifedipine. Drug Metab Dispos 37, 651-657 (2009).

12. Fang, C. \& Zhang, Q. Y. The role of small-intestinal P450 enzymes in protection against systemic exposure of orally administered benzo[a]pyrene. J Pharmacol Exp Ther 334, 156-163 (2010).

13. Zhu, Y., D’Agostino, J. \& Zhang, Q. Y. Role of intestinal cytochrome P450 (P450) in modulating the bioavailability of oral lovastatin: insights from studies on the intestinal epithelium-specific P450 reductase knockout mouse. Drug Metab Dispos 39, 939-943 (2011).

14. Zhu, Y. \& Zhang, Q. Y. Role of intestinal cytochrome p450 enzymes in diclofenacinduced toxicity in the small intestine. J Pharmacol Exp Ther 343, 362-370 (2012).

15. D'Agostino, J. et al. Potential biological functions of cytochrome $\mathrm{P} 450$ reductasedependent enzymes in small intestine: novel link to expression of major histocompatibility complex class II genes. J Biol Chem 287, 17777-17788 (2012).

16. Griffin, A. J. \& McSorley, S. J. Development of protective immunity to Salmonella, a mucosal pathogen with a systemic agenda. Mucosal Immunol, 4, 371-382 (2011).

17. McSorley, S. J., Asch, S., Costalonga, M., Reinhardt, R. L. \& Jenkins, M. K. Tracking salmonella-specific CD4 T cells in vivo reveals a local mucosal response to a disseminated infection. Immunity 16, 365-377 (2002).

18. Yoder, J. M., Aslam, R. U. \& Mantis, N. J. Evidence for widespread epithelial damage and coincident production of monocyte chemotactic protein 1 in a murine model of intestinal ricin intoxication. Infect Immun 75, 1745-1750 (2007).

19. Nielsen, K. \& Boston, R. S. Ribosome-Inactivating Proteins:A Plant Perspective. Ann Rev Plant Physiol Plant Mol Biol 52, 785-816 (2001)

20. Stirpe, F. Ribosome-inactivating proteins. Toxicon 44, 371-383 (2004).
21. Johansen, F. E. et al. Absence of epithelial immunoglobulin A transport, with increased mucosal leakiness, in polymeric immunoglobulin receptor/secretory component-deficient mice. J Exp Med 190, 915-922 (1999).

22. Johansen, F. E. \& Kaetzel, C. S. Regulation of the polymeric immunoglobulin receptor and IgA transport: new advances in environmental factors that stimulate pIgR expression and its role in mucosal immunity. Mucosal Immunol 4, 598-602 (2011).

23. Bergqvist, P. et al. Re-utilization of germinal centers in multiple Peyer's patches results in highly synchronized, oligoclonal, and affinity-matured gut IgA responses. Mucosal Immunol 6, 122-135 (2013).

24. Ross, A. C. \& Zolfaghari, R. Cytochrome P450s in the regulation of cellular retinoic acid metabolism. Annu Rev Nutr 31, 65-87 (2011).

25. Zhang, Q. Y., Raner, G., Ding, X., Dunbar, D., Coon, M. J. \& Kaminsky, L. S Characterization of the cytochrome P450 CYP2J4: expression in rat small intestine and role in retinoic acid biotransformation from retinal. Arch Biochem Biophys 353, 257-264 (1998).

26. Campbell, W. B. New role for epoxyeicosatrienoic acids as anti-inflammatory mediators. Trends Pharmacol Sci 21, 125-127 (2000).

27. Node, K. et al. Anti-inflammatory properties of cytochrome P450 epoxygenasederived eicosanoids. Science 285, 1276-1279 (1999).

28. Thomson, S. J., Askari, A. \& Bishop-Bailey, D. Anti-inflammatory effects of epoxyeicosatrienoic acids. Int J Vasc Med. 2012, 605101 (2012).

29. Blikslager, A. T., Moeser, A. J., Gookin, J. L., Jones, S. L. \& Odle, J. Restoration of barrier function in injured intestinal mucosa. Physiol Rev 87, 545-564 (2007)

30. Mantis, N. J., McGuinness, C. R., Sonuyi, O., Edwards, G. \& Farrant, S. A. Immunoglobulin A antibodies against ricin A and B subunits protect epithelial cells from ricin intoxication. Infect Immun 74, 3455-3462 (2006).

31. van Deurs, B., Hansen, S. H., Petersen, O. W., Melby, E. L. \& Sandvig, K. Endocytosis, intracellular transport and transcytosis of the toxic protein ricin by a polarized epithelium. EurJCell Biol 51, 96-109 (1990).

32. Bassik, M. C. et al. A systematic mammalian genetic interaction map reveals pathways underlying ricin susceptibility. Cell 152, 909-922 (2013).

33. Jandhyala, D. M., Ahluwalia, A., Obrig, T. \& Thorpe, C. M. ZAK: a MAP3Kinase that transduces Shiga toxin- and ricin-induced proinflammatory cytokine expression. Cell Microbiol 10, 1468-1477 (2008)

34. Thorpe, C. M., Hurley, B. P., Lincicome, L. L., Jacewicz, M. S., Keusch, G. T. \& Acheson, D. W. Shiga toxins stimulate secretion of interleukin-8 from intestinal epithelial cells. InfectImmun 67, 5985-5993 (1999).

35. Thorpe, C. M., Smith, W. E., Hurley, B. P. \& Acheson, D. W. Shiga toxins induce, superinduce, and stabilize a variety of C-X-C chemokine mRNAs in intestinal epithelial cells, resulting in increased chemokine expression. Infect Immun 69, 6140-6147 (2001).

36. Yamasaki, C. et al. Induction of cytokines by toxins that have an identical RNA Nglycosidase activity: Shiga toxin, ricin, and modeccin. Biochim Biophys Acta 1671 44-50 (2004)

37. Spooner, R. A. \& Lord, J. M. How Ricin and Shiga Toxin Reach the Cytosol of Target Cells: Retrotranslocation from the Endoplasmic Reticulum. Curr Top Microbiol Immunol 357, 19-40 (2012).

38. Neal, L. M., McCarthy, E. A., Morris, C. R. \& Mantis, N. J. Vaccine-induced intestinal immunity to ricin toxin in the absence of secretory IgA. Vaccine 29, 681-689 (2011)

39. Hershberg, R. M. et al. Highly polarized HLA class II antigen processing and presentation by human intestinal epithelial cells. J Clin Invest 102, 792-803 (1998).

40. Thelemann, C. et al. Interferon-gamma induces expression of MHC class II on intestinal epithelial cells and protects mice from colitis. PLoS One 9, e86844 (2014).

41. Brandtzaeg, P. Secretory IgA: Designed for Anti-Microbial Defense. Front Immunol 4, 222 (2013).

42. Mantis, N. J., Rol, N. \& Corthesy, B. Secretory IgA's complex roles in immunity and mucosal homeostasis in the gut. Mucosal Immunol 4, 603-611 (2011).

43. Pabst, O. New concepts in the generation and functions of IgA. Nat Rev Immunol 12, 821-832 (2012).

44. Luton, F., Verges, M., Vaerman, J. P., Sudol, M. \& Mostov, K. E. The SRC family protein tyrosine kinase p62yes controls polymeric IgA transcytosis in vivo. $\mathrm{Mol}$ Cell 4, 627-632 (1999).

45. Mostov, K., Su, T. \& ter Beest, M. Polarized epithelial membrane traffic: conservation and plasticity. Nat Cell Biol 5, 287-293 (2003).

46. Panigrahy, D. et al. Epoxyeicosanoids promote organ and tissue regeneration. Proc Natl Acad Sci U S A 110, 13528-13533 (2013).

47. Paul, G. et al. Analysis of intestinal haem-oxygenase-1 (HO-1) in clinical and experimental colitis. Clin Exp Immunol 140, 547-555 (2005).

48. Willis, D., Moore, A. R., Frederick, R. \& Willoughby, D. A. Heme oxygenase: a novel target for the modulation of the inflammatory response. Nat Med 2, 87-90 (1996).

49. Zhang, Q. Y., Dunbar, D. \& Kaminsky, L. S. Characterization of mouse small intestinal cytochrome P450 expression. Drug Metab Dispos 31, 1346-1351 (2003).

50. Resendiz-Albor, A. A. et al. Regionalization of pIgR expression in the mucosa of mouse small intestine. Immunol Lett 128, 59-67 (2010).

51. Kane, M. A., Folias, A. E., Wang, C. \& Napoli, J. L. Quantitative profiling of endogenous retinoic acid in vivo and in vitro by tandem mass spectrometry. Anal Chem 80, 1702-1708 (2008). 
52. Carvalho, V. M., Nakamura, O. H. \& Vieira, J. G. Simultaneous quantitation of seven endogenous $\mathrm{C}-21$ adrenal steroids by liquid chromatography tandem mass spectrometry in human serum. J Chromatogr B Analyt Technol Biomed Life Sci 872, 154-161 (2008).

53. Di Marzo, V. et al. Leptin-regulated endocannabinoids are involved in maintaining food intake. Nature 410, 822-825 (2001).

54. Martin-Venegas, R., Casillas, R., Jauregui, O. \& Moreno, J. J. Rapid simultaneous analysis of cyclooxygenase, lipoxygenase and cytochrome P-450 metabolites of arachidonic and linoleic acids using high performance liquid chromatography/ mass spectrometry in tandem mode. J Pharm Biomed Anal 56, 976-982 (2011).

55. De Jesus, M., Ahlawat, S. \& Mantis, N. J. Isolating And Immunostaining Lymphocytes and Dendritic Cells from Murine Peyer's Patches. J Vis Exp 73, e50167 (2013).

\section{Acknowledgments}

We thank Richard A. Cole (Advanced Light Microscopy Core, Wadsworth Center) for assistance with confocal microscopy and image collection, Renjie Song (Immunology Core, Wadsworth Center) for assistance with flow cytometry, and Helen Johnson (Animal Histopathology Core, facility) for embedding, sectioning, and staining mouse tissues. We thank Dr. John Varrone and Dr. David Vance for assistance with Salmonella and ricin challenge studies, respectively, and Ms. Weizhu Yang for assistance with mouse breeding and maintenance. This work was supported in part by a Wadsworth Center-Health Research, Inc intramural award, and by National Institute Health grants R01HD061916 to N.J.M.) from the Eunice Kennedy Shriver National Institute of Child Health and Human
Development (NICHD) and R01GM082978 (to Q-Y.Z.) from the National Institute of General Medical Science (GMS).

\section{Author contributions}

S.A. and F.X. (equal contributors) conducted the experiments and analyzed the data described in this manuscript; Y.Z. and R.D. assisted with the mouse studies. X.D., Q.Z. and N.M. were responsible for experimental design, data analysis and final preparation of the manuscript.

\section{Additional information}

Supplementary information accompanies this paper at http://www.nature.com/ scientificreports

Competing financial interests: The authors declare no competing financial interests. How to cite this article: Ahlawat, S. et al. Mice Deficient in Intestinal Epithelium Cytochrome P450 Reductase are Prone to Acute Toxin-induced Mucosal Damage. Sci. Rep. 4, 5551; DOI:10.1038/srep05551 (2014).

This work is licensed under a Creative Commons Attribution-NonCommercialNoDerivs 4.0 International License. The images or other third party material in this article are included in the article's Creative Commons license, unless indicated otherwise in the credit line; if the material is not included under the Creative Commons license, users will need to obtain permission from the license holder in order to reproduce the material. To view a copy of this license, visit http:// creativecommons.org/licenses/by-nc-nd/4.0/ 